\title{
Biopolymer Hydrogel Based on Acid Whey and Cellulose Derivatives for Enhancement Water Retention Capacity of Soil and Slow Release of Fertilizers
}

\author{
Silvie Durpekova *, Antonio Di Martino, Miroslava Dusankova, Petra Drohsler (D) and Vladimir Sedlarik
}

check for updates

Citation: Durpekova, S.; Di Martino, A.; Dusankova, M.; Drohsler, P.; Sedlarik, V. Biopolymer Hydrogel Based on Acid Whey and Cellulose Derivatives for Enhancement Water Retention Capacity of Soil and Slow Release of Fertilizers. Polymers 2021 13, 3274. https://doi.org/10.3390/ polym13193274

Academic Editor: Ki Hyun Bae

Received: 24 August 2021

Accepted: 23 September 2021

Published: 25 September 2021

Publisher's Note: MDPI stays neutral with regard to jurisdictional claims in published maps and institutional affiliations.

Copyright: (C) 2021 by the authors Licensee MDPI, Basel, Switzerland. This article is an open access article distributed under the terms and conditions of the Creative Commons Attribution (CC BY) license (https:// creativecommons.org/licenses/by/ $4.0 /)$.
Centre of Polymer Systems, University Institute, Tomas Bata University in Zlin, Tr. T. Bati 5678, 76001 Zlin, Czech Republic; dimartino@utb.cz (A.D.M.); Miroslava.Urbankova@seznam.cz (M.D.); pvalkova@utb.cz (P.D.); sedlarik@utb.cz (V.S.)

* Correspondence: durpekova@utb.cz

\begin{abstract}
This study describes the development of a renewable and biodegradable biopolymer-based hydrogel for application in agriculture and horticulture as a soil conditioning agent and for release of a nutrient or fertilizer. The novel product is based on a combination of cellulose derivatives (carboxymethylcellulose and hydroxyethylcellulose) cross-linked with citric acid, as tested at various concentrations, with acid whey as a medium for hydrogel synthesis in order to utilize the almost unusable by-product of the dairy industry. The water uptake of the hydrogel was evaluated by swelling tests under variations in $\mathrm{pH}$, temperature and ion concentration. Its swelling capacity, water retention and biodegradability were investigated in soil to simulate real-world conditions, the latter being monitored by the production of carbon dioxide during the biodegradation process by gas chromatography. Changes in the chemical structure and morphology of the hydrogels during biodegradation were assessed using Fourier transform infrared spectroscopy and scanning electron microscopy. The ability of the hydrogel to hold and release fertilizers was studied with urea and $\mathrm{KNO}_{3}$ as model substances. The results not only demonstrate the potential of the hydrogel to enhance the quality of soil, but also how acid whey can be employed in the development of a soil conditioning agent and nutrient release products.
\end{abstract}

Keywords: biopolymer hydrogel; acid whey; cellulose derivatives; citric acid; swelling properties; soil improvement

\section{Introduction}

The agricultural sector is a major consumer of water, one that utilizes in excess of $70 \%$ of the available water resources for growing crops and producing foodstuffs [1]. Recent years have witnessed a scarcity of rainfall, seriously complicating irrigation efforts and highlighting the importance of water management in the future. As a consequence, a great deal of research has been directed at developing superabsorbent hydrogel materials for agricultural use with the aim of ensuring the efficient utilization of water and the sustainability of soil [1-3]. Hydrogels intended for agriculture primarily comprise soil conditioners for controlled moistening of the environment, which heightens the water holding capacity of the soil, supply water to plants to encourage growth and serve for the sustained release of fertilizers [3,4]. As a result of the emphasis on environmental protection in recent times, great interest has been shown in developing biodegradable hydrogels based on renewable bioresources (e.g., derivatives from agricultural crops or industrial byproducts) [5-7]. Such environmentally friendly hydrogels have found various applications, including in agriculture, due to their low-cost, sustainability and biodegradability $[6,8]$.

This study deploys acid whey as a primary component in a hydrogel designed as a soil conditioner capable of the gradual release of a fertilizer, the aim being to effectively utilize a waste product of the dairy industry and reduce associated pollution. Since the hydrogel 
is based on acid whey, it also has the potential to act as a nutritive agent for boosting the growth, yield and quality of crops due to the high content of organic compounds present in the whey [9].

In this work, a combination of two renewable biopolymers (the cellulose derivatives sodium carboxymethylcellulose (CMCNa) and hydroxyethylcellulose (HEC)) as the form of the polysaccharide/whey-based hydrogel was used. Compared to conventional types originating from acrylate, hydrogels with the $\mathrm{CMCNa} / \mathrm{HEC}$ binary system demonstrate similar swelling properties and high biodegradability $[10,11]$. In particular, $\mathrm{CMCNa}$ as a polyelectrolyte species, enhances the swelling capacity and sensitivity of a hydrogel to environmental stimuli (i.e., ionic strength and $\mathrm{pH}$ ) as a consequence of the Gibbs-Donnan effect [11]. However, poor cross-linking efficiency has been reported when only $\mathrm{CMCNa}$ is used, stemming from electrostatic repulsion between the charged macromolecules of polyelectrolyte chains which tends to form intramolecular rather than intermolecular crosslinking. For this reason, a mixtures of CMCNa with HEC was used for hydrogel formation, as the introduction of HEC avoids the formation of intramolecular crosslinking, thereby stabilizing the macromolecules in a three-dimensional polymer network [12]. In order to design the fully biodegradable and environmentally friendly hydrogel, a naturally occurring and easily biodegradable citric acid (CA) was applied as a non-toxic alternative to chemical crosslinkers. Hydrogels cross-linked with CA have proven to be stiff enough to maintain their shape and high swelling ratio [10].

This work investigates the effects of different cross-linking concentrations and external stimuli on the swelling behavior of the novel hydrogel. Its water retention and biodegradability in soil are determined, while study of the release of fertilizers (urea and potassium nitrate) from the hydrogel reveals its potential for agricultural and horticultural use.

\section{Materials and Methods}

\subsection{Materials}

Carboxymethylcellulose sodium salt (CMCNa) (Blanose 7HOF, with MW $7 \times 10^{5} \mathrm{Da}$, DS $=0.7$, viscosity $1000-2800 \mathrm{cp}\left(1 \%, 25^{\circ} \mathrm{C}\right)$ ) and hydroxyethylcellulose (HEC) (Natrosol $250 \mathrm{HR}$, with MW $106 \mathrm{Da}$, MS = 2.5, viscosity $1500-2500 \mathrm{cp}\left(1 \%, 25^{\circ} \mathrm{C}\right)$ ) were purchased from Ashland (Ashland, OH, USA). Acid whey was sourced from Milcom, a.s. (Prague, Czech Republic), as a by-product of the manufacture of cream cheese. Citric acid in anhydrous form $\left(\mathrm{C}_{6} \mathrm{H}_{8} \mathrm{O}_{7}\right.$, Sigma-Aldrich, Milano, Italy) was employed for the crosslinking reaction. Urea $\left(\mathrm{CH}_{4} \mathrm{~N}_{2} \mathrm{O}\right.$, Lach-Ner, Neratovice, Czech Republic) and potassium nitrate $\left(\mathrm{KNO}_{3}\right.$, Sigma-Aldrich, Milano, Italy) were used for loading capacity of fertilizers and release study.

\subsection{Preparation of the Hydrogel}

Samples were prepared according to a procedure described in Durpekova et al. [13], with minor modification. Briefly, a mixture of the $\mathrm{CMCNa}$ and $\mathrm{HEC}$ at a weight ratio equal to $3: 1$ and total polymer concentration of $3 \mathrm{wt} \%$ was dissolved in the untreated acid whey under mechanical stirring at room temperature $\left(20-22{ }^{\circ} \mathrm{C}\right)$ for $24 \mathrm{~h}$ until a homogeneous solution was obtained. Afterwards, CA at defined concentrations $(5,10$ and $15 \% w / w$ of the polymer) was added into the solution to obtain different degrees of cross-linking. The cross-linking reaction was achieved during the following drying at $60^{\circ} \mathrm{C}$ for $24 \mathrm{~h}$. The samples prepared in this manner are listed in Table 1.

Table 1. Composition of the hydrogel samples.

\begin{tabular}{ccc}
\hline Sample Designation & $\begin{array}{c}\text { Cellulose Derivatives } \\
(\mathbf{\%} \boldsymbol{w} / \boldsymbol{w})\end{array}$ & $\begin{array}{c}\text { Citric Acid } \\
\mathbf{( \%} \boldsymbol{w} / \boldsymbol{w})\end{array}$ \\
\hline HCA5 & 3 CMC/HEC $(3: 1)$ & 5 \\
HCA10 & 3 CMC/HEC $(3: 1)$ & 10 \\
HCA15 & 3 CMC/HEC $(3: 1)$ & 15 \\
\hline
\end{tabular}




\subsection{Hydrogel Characterization}

\subsubsection{Gel Fraction}

To measure the gel fractions of cross-linked hydrogels, the dried hydrogel samples were immersed in distilled water for $48 \mathrm{~h}$, at room temperature until a constant weight was reached. The samples were then dried in vacuum oven (Memmert VO400, Swabach, Germany) at a temperature of $40^{\circ} \mathrm{C}$ until it had reached constant weight again. The gel fraction (GF) was calculated ac-cording to the following Equation (1):

$$
\mathrm{GF}(\%)=\frac{\mathrm{W}_{\mathrm{d}}}{\mathrm{W}_{\mathrm{i}}} \times 100
$$

where $W_{i}$ is the initial weight of dried sample and $W_{d}$ is the weight of dried gel sample after the extraction with deionized water.

\subsubsection{Swelling Ratio (SR) under Various Conditions}

The values for SR of the hydrogels were measured in triplicate via the gravimetric method in solutions of different $\mathrm{pH}(\mathrm{pH} 2-10)$, ionic strength $(0.001-1.0 \mathrm{M} \mathrm{NaCl})$ and temperature of the media $\left(10-50^{\circ} \mathrm{C}\right)$. In brief, $3 \mathrm{~g}$ of the dried hydrogel was soaked in distilled water for $24 \mathrm{~h}$ in the laboratory. The $\mathrm{pH}$ of the solutions was adjusted by $1.0 \mathrm{M}$ $\mathrm{NaOH}$ and $0.1 \mathrm{M} \mathrm{HCl}$ to obtain the given range of $\mathrm{pH}$. The kinetics of swelling were measured by taking the hydrogel out of the solution at defined intervals of time $(5,10,15$, $20,30,60,180,240$ and $1440 \mathrm{~min}$ ), then excess media was removed with filter paper and the weight recorded. The SR was determined by weighing the samples before and after immersion in distilled water for $24 \mathrm{~h}$ using the following Equation (2):

$$
\operatorname{SR}(\%)=\left(\frac{W_{\mathrm{s}}-\mathrm{W}_{\mathrm{d}}}{\mathrm{W}_{\mathrm{d}}}\right) \times 100
$$

where $W_{s}$ and $W_{d}$ are the masses of the swollen and dried samples (g), respectively.

\subsubsection{Water-Holding Capacity (WHC) in Soil}

The efficiency of the prepared hydrogel to retain water in soil was expressed in terms of WHC. In this experiment, the soil was dried at $45^{\circ} \mathrm{C}$ until it had reached constant weight. An amount of $1 \mathrm{~g}$ of the dried hydrogel ( $5 \mathrm{~mm}$ in diameter) was thoroughly mixed with $50 \mathrm{~g}$ of the dried soil and transferred into a plastic pot $\left(\mathrm{W}_{1}\right)$. The bottom of the pot was fitted with a filter paper used for leaking out of un-holding water. Pure soil was used as the control $\left(\mathrm{W}_{0}\right)$. The weight of each pot was measured afterwards, then $50 \mathrm{~mL}$ of distilled water was added, and the weight was recorded again $\left(\mathrm{W}_{2}\right)$. The WHC was calculated according to Equation (3) as follows:

$$
\operatorname{WHC}(\%)=\frac{\left(\mathrm{W}_{2}-\mathrm{W}_{1}\right)}{\mathrm{W}_{0}} \times 100
$$

\subsubsection{Water-Retention (WR)}

The samples from WHC study were then stored at controlled laboratory temperature $\left(22{ }^{\circ} \mathrm{C}\right)$ and the weight monitored daily until no detectable weight loss was observed. Equation (4) below gave values for WR:

$$
\mathrm{WR}(\%)=\frac{\mathrm{W}_{\mathrm{t}}-\mathrm{W}}{\mathrm{W}_{\mathrm{i}}-\mathrm{W}} \times 100
$$

where $\mathrm{W}$ is the weight of the sample without water, $\mathrm{W}_{\mathrm{i}}$ is the weight of the sample after adding the water and $W_{t}$ refers to the weight of the sample after specified time intervals. 


\subsubsection{Reswelling Capacity (RSC) in Free Water and Soil}

The RSC capacity of the hydrogels was evaluated in media and soil. In the former of the two, a defined amount of the hydrogel was swollen in distilled water until equilibrium had been reached, as described above for SR (2.3.1.). The swollen hydrogels were subsequently dried at $40^{\circ} \mathrm{C}$ until no variation in weight was observed, upon which they were re-immersed in distilled water until equilibrium was obtained again.

The RSC in soil was investigated as follows. The moist soil samples from WHC study (2.3.2.) were dried at $45^{\circ} \mathrm{C}$ to constant weight. After that, $50 \mathrm{~mL}$ of distilled water was slowly poured into each pot and the samples were weighed again. This procedure of swelling, drying and swelling was repeated five times for each hydrogel sample to determine the reversibility of the hydrogel and its potential for water reabsorption. The RSC (in percent) of the hydrogel was calculated for each reswelling cycle according to Equation (1) for the SR given above.

\subsubsection{Biodegradability of the Hydrogel Using Soil Burial Method}

The biodegradability of the hydrogel was studied through burial in garden soil ( $\mathrm{pH} \sim 6.0)$ [14]. Hydrogel samples of defined size $\left(2 \times 20 \mathrm{~mm}^{2}\right)$ were placed approximately $10 \mathrm{~cm}$ beneath the surface of the soil in the pots. Thereafter, $20 \mathrm{~mL}$ of water was added to each pot, which was kept at room temperature. Water was supplemented as necessary to replenish the soil samples as they dried through evaporation. The weight of each sample was measured at 5-day intervals. The hydrogel samples were taken out, washed gently to remove the soil from surface and dried at $45^{\circ} \mathrm{C}$. Their extent of degradation was monitored at different stages of biodegradation by visual evaluation, changes in morphology (SEM), chemical structure (FTIR) and calculation of weight loss (WL) according to Equation (5) as follows:

$$
\mathrm{WL}(\%)=\frac{\mathrm{W}_{\mathrm{i}}-\mathrm{W}_{\mathrm{f}}}{\mathrm{W}_{\mathrm{i}}} \times 100
$$

where $\mathrm{W}_{\mathrm{i}}$ is the initial weight of samples before starting the degradation, whereas $\mathrm{W}_{\mathrm{f}}$ refers to the weight of the sample after specified time intervals of biodegradation.

\subsubsection{Scanning Electron Microscopy}

The surface texture of the hydrogel and its inner structure as well as changes in the physical structure of the hydrogel when in soil were investigated using scanning electron microscopy (SEM). Dried hydrogels were mounted on to the base platform for gold coating using vacuum sputter coater in a vacuum of $3 \times 10^{-1} \mathrm{~atm}$ of argon gas. The coated samples were then analyzed using a scanning electron microscope Nova NanoSEM 450 unit set to an operating voltage of $10 \mathrm{kV}$.

\subsubsection{Attenuated Total Reflectance-Fourier Transform Infrared (ATR-FTIR) Spectroscopy}

Infrared spectra for the hydrogel and changes that had occurred in chemical structure through burial in the soil were recorded on a Thermo NICOLET 6700 spectrometer via the ATR technique. The unit was equipped with a diamond crystal and set to the resolution of $2 \mathrm{~cm}^{-1}$ and range of absorbance of $400-4000 \mathrm{~cm}^{-1}$. At predetermined intervals, the samples were removed from the soil, cleaned and analyzed using FTIR.

\subsubsection{GC Analysis of Biodegradation in Soil}

A prescribed procedure was adhered to by Sera et al. [15]. In total, $100 \mathrm{mg}$ of dry hydrogel, $5 \mathrm{~g}$ of perlite and $5 \mathrm{~g}$ of soil of dry weight were weighed out and transferred into 500-milliliter biometric flasks. The flasks were sealed with stoppers equipped with septa and incubated at $25^{\circ} \mathrm{C}$. Headspace gas was sampled at appropriate intervals through the septum with a gas-tight syringe and then injected manually into the GC instrument (GC-2010 Plus, Shimadzu Europa GmbH, Germany), equipped with Porapak Q (1.829 m length, 80/100 MESH) and 5A-molecular-sieve (1.829 m length, 60/80 MESH) packed columns connected in series, as well as a thermal conductivity detector (carrier gas, helium; 


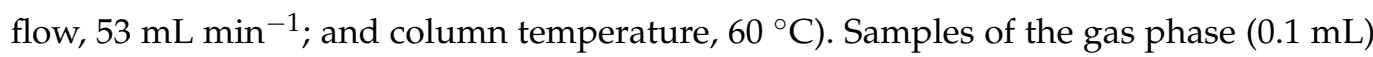
were taken and analyzed every week. The concentrations of $\mathrm{CO}_{2}$ and $\mathrm{O}_{2}$ were derived from the calibration curve obtained, using a calibration gas mixture with declared composition. The percentage of mineralization pertaining to the carbon content of the initial sample was calculated from the $\mathrm{CO}_{2}$ concentration found. Endogenous production of $\mathrm{CO}_{2}$ by soil in blank incubations was always subtracted to obtain values representing net sample mineralization. Since the blank sample comprised $5 \mathrm{~g}$ of soil matter without the presence of a hydrogel sample, any production of $\mathrm{CO}_{2}$ related entirely to the soil. From the concentration determined, the value for mineralization ( $\mathrm{M}$, in per cent) relating to the initial carbon content of the sample was calculated as follows in Equation (6):

$$
\mathrm{M}=\frac{\mathrm{m}_{\mathrm{gc}}}{\mathrm{m}_{\mathrm{s}} \mathrm{w}_{\mathrm{c}}}
$$

where $\mathrm{m}_{\mathrm{gc}}(\mathrm{mg})$ is the mass of carbon evolved as $\mathrm{CO}_{2}$ and obtained from GC analysis, $\mathrm{m}_{\mathrm{s}}$ $(\mathrm{mg})$ is the weight of the polymer sample and $\mathrm{w}_{\mathrm{c}}$ is the percentage $(w / w)$ of carbon in the material investigated. The value of $\mathrm{w}_{\mathrm{c}}$ for the given polymer was determined on a total organic carbon (TOC) analyzer (TOC-L, Shimadzu Europa GmbH, Duisburg, Germany), equipped with a solid sample module (SSM-5000A, Shimadzu). Three parallel flasks were run for each sample, along with four blanks.

\subsubsection{Loading of the Fertilizers}

Two sets of hydrogels were prepared; the first contained a single fertilizer, while the other was a combination at the mass ratio of 1:1. The dried hydrogels were soaked in $200 \mathrm{~mL}$ of an aqueous solution containing the fertilizer $(0.1 \mathrm{M})$ for $1,6,12$ and $24 \mathrm{~h}$ to discern maximum adsorption over time. After reaching to the equilibrium the loaded hydrogels were washed with deionized water and dried in vacuum at $40{ }^{\circ} \mathrm{C}$. The amount of fertilizer(s) loaded (L) was obtained using Equation (7):

$$
\mathrm{L}(\%)=\left(\frac{\mathrm{M}_{\mathrm{n}}-\mathrm{M}_{0}}{\mathrm{M}_{0}}\right) \times 100
$$

where $\mathrm{M}_{\mathrm{n}}$ is the weight (in $\mathrm{mg}$ ) of the previously dried hydrogel after being soaked for time $n$ in the solution, while $\mathrm{M}_{0}$ is the initial weight of the dried hydrogel.

For the simultaneous loading of $\mathrm{KNO}_{3}$ and urea, the same procedure was applied, the only difference being that the previously dried hydrogel was soaked in aqueous solution containing $\mathrm{KNO}_{3} 0.1 \mathrm{M}$ and urea $0.1 \mathrm{M}$.

\subsubsection{Release Studies in Soil Extract}

The individual and simultaneous release of the fertilizers, $\mathrm{KNO}_{3}$ and urea from the hydrogel was performed in soil extract. The soil extract was obtained as follows: $20 \mathrm{~g}$ of soil was soaked in $1 \mathrm{~L}$ of distilled water and placed under an oscillating shaker at $40^{\circ} \mathrm{C}$ for $48 \mathrm{~h}$. Afterwards, the solid material was separated out by filtration and the resulting liquid used as the release media. The weight of the dried hydrogel containing the fertilizer(s) was recorded prior to the sample being placed in $200 \mathrm{~mL}$ of the extract. At a scheduled time, an aliquot of the media was withdrawn and analyzed for $\mathrm{KNO}_{3}$ and/or urea content. The $\mathrm{KNO}_{3}$ in the media was determined by variation in the conductivity of the media by a conductivity meter (Gryf $158 \mathrm{HB}$, Czech Republic), whereas the amount of urea was quantified spectroscopically at $245 \mathrm{~nm}$ on a UV spectrophotometer (Cary $300 \mathrm{UVeVis}$ Agilent, Santa Clara, CA, USA) after treatment with 4-(Dimethylamino) benzaldehyde (40 mmol/L). 


\section{Results and Discussion}

\subsection{Swelling Properties}

3.1.1. Effect of Temperature, $\mathrm{pH}$ and Ionic Strength (External Stimuli) of the Immersed Medium on the Degree of Swelling

One of the key properties for hydrogels designed as a soil conditioner is the capacity to absorb and then hold a high volume of water. The swelling results of the proposed hydrogels based on polysaccharide/whey demonstrate its high swelling capacity (1000-1400\%), which is comparable with many cellulose- $[10,12,16]$, starch- [17-19] or chitosan $[20,21]$ based superabsorbent hydrogels obtained with water as the preparation media. Such behaviour can be ascribed to the large amount of water that penetrated and was displaced within the hydrogel matrix as a result of heightened Gibbs free energy in the solution, thereby favouring diffusion [22].

Swelling kinetics under different conditions of immersed medium was evaluated herein by measuring the water uptake at certain intervals, at $\mathrm{pH} 2-10$, the ionic strength of $0.001-1.0 \mathrm{M} \mathrm{NaCl}$ and temperatures of $10-50^{\circ} \mathrm{C}$, so as to determine the effects of such external stimuli on the swelling behavior of the hydrogel samples. Variations in the swelling behavior of hydrogel H5CA are given in Figures 1-3. The results reveal that a relationship exists between the temperature and the swelling capacity. As Figure 1 shows, the greatest capacity is evident at higher temperatures, possibly caused by thermal expansion of the hydrogel network and destruction of hydrogen bonding between the polymer molecules; such actions leading to the expansion of the hydrogel matrix after diffusion of the water into the porous structure of the hydrogel [23]. In contrast, the least extent of water uptake was observed when the immersed distilled water was at a low temperature $\left(10^{\circ} \mathrm{C}\right)$; this occurred as a consequence of minimal internal energy and entropy, in turn, leading to limited movement and reduced diffusion of the solution into the internal structure of the hydrogel [24].

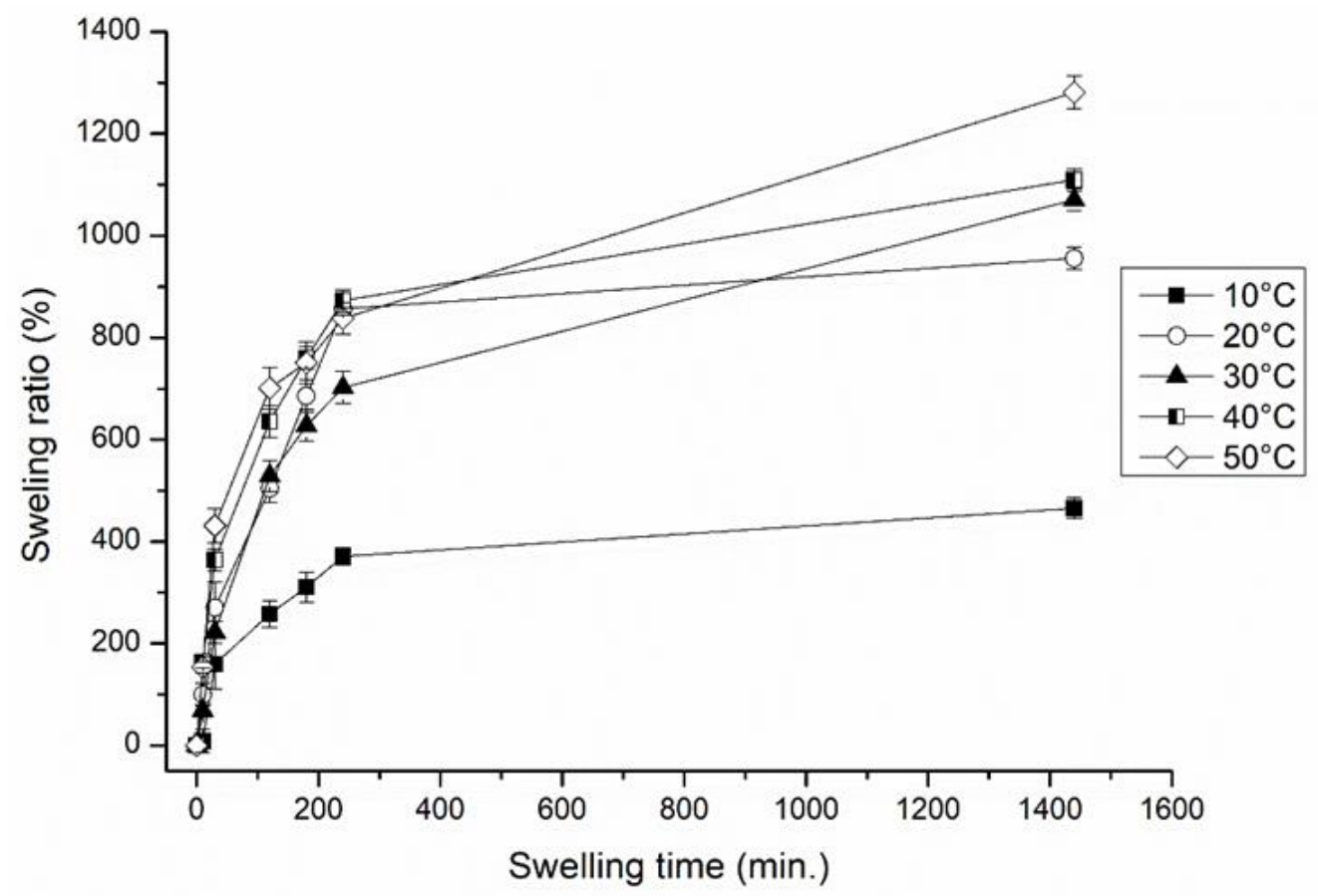

Figure 1. Swelling ratio (\%) for hydrogel H5CA immersed in distilled water at different temperatures. The data comprise mean values for SR derived from three instances of water uptake (in weight $\pm \mathrm{SD} ; \mathrm{n}=3$ ). 


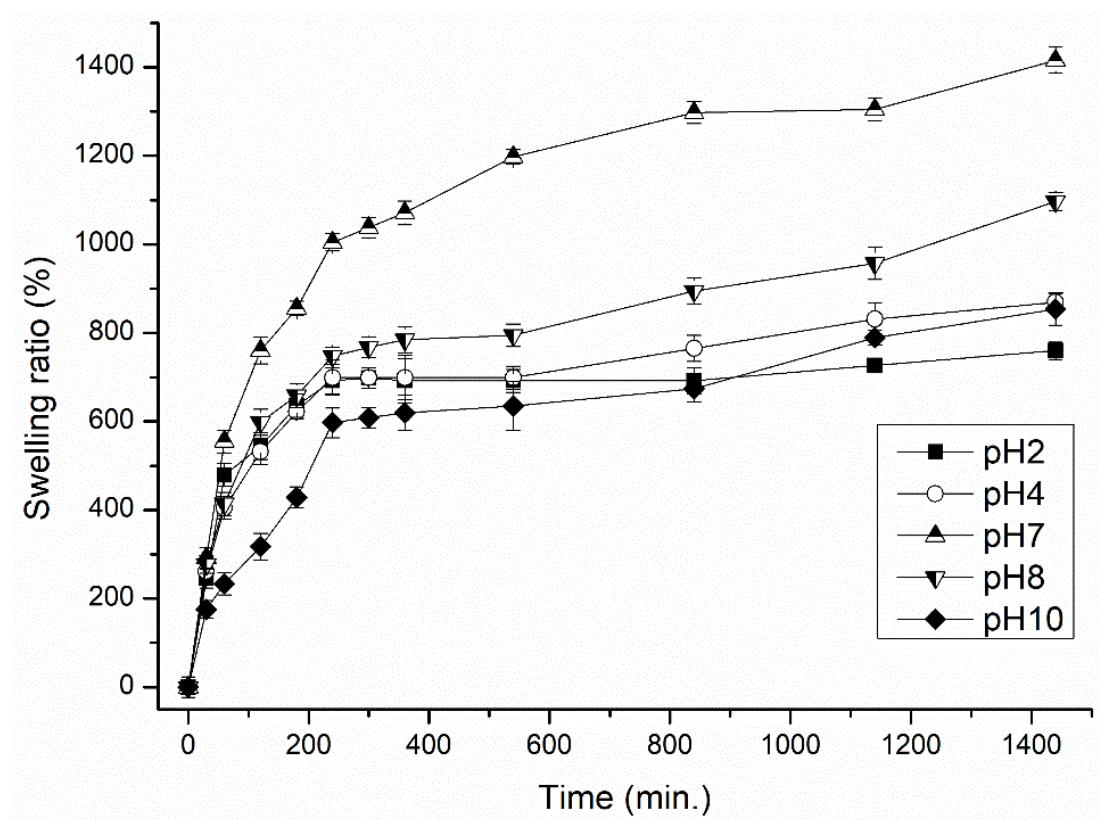

Figure 2. Effect of acidic ( $\mathrm{pH} 2$ and 4), neutral ( $\mathrm{pH} 7)$ and saline ( $\mathrm{pH} 8$ and 10) swelling media on swelling behavior (SR \%) by hydrogel H5CA within $24 \mathrm{~h}$ of swelling. Data refer to the mean value $\pm S D(n=3)$.

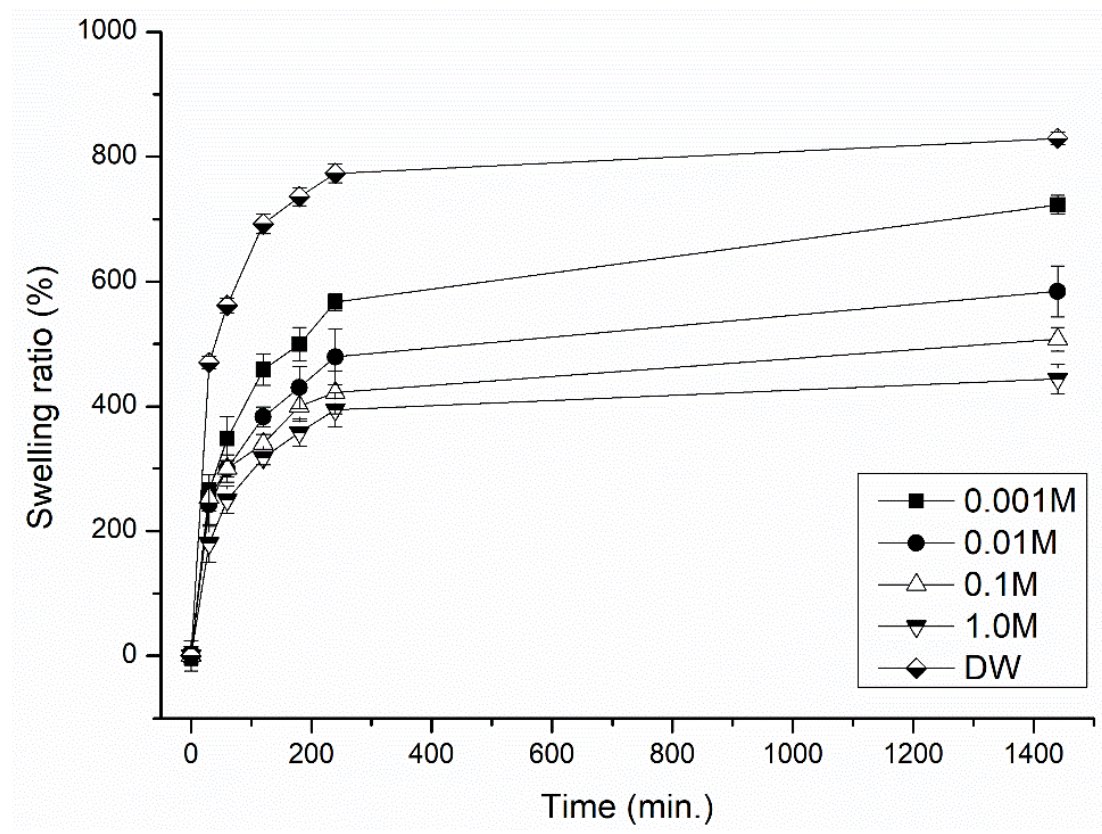

Figure 3. Dependence of ionic strength (concentration of salt) in water on the swelling behavior $(\mathrm{SR} \%)$ of the hydrogel H5CA. Data refer to mean values $\pm \mathrm{SD}(\mathrm{n}=3)$.

Under conditions of low temperature $\left(10^{\circ} \mathrm{C}\right)$, water uptake was slow at the commencement of the swelling process, with the SR stabilizing after $3 \mathrm{~h}$. At a higher temperature $\left(50{ }^{\circ} \mathrm{C}\right)$, however, a significant increase in the SR was observed within the first few hours, followed by a gradual rise. An equilibrium in swelling was reached after $24 \mathrm{~h}$ of exposure to the media. Such behavior can be ascribed to the large amount of water that penetrated and was displaced within the hydrogel matrix as a result of heightened Gibbs free energy in the solution, thereby favoring diffusion [22].

The $\mathrm{pH}$ of the media and $\mathrm{pKa}$ values for the acidic groups in the polymer structure are fundamental to the regulation of swelling properties. A change in the $\mathrm{pH}$ of the swelling medium directly impacts the volume of water uptake $[25,26]$. Swelling media differing 
from $\mathrm{pH}$ were employed to evaluate the impact of $\mathrm{pH}$ on the swelling capacity of the polysaccharide/whey-based hydrogel. The graph in Figure 2 shows that a considerable decrease in swelling capacity is evident in the acidic medium at pH 2 and 4 . Such behaviour is associated with the presence of $\mathrm{pH}$-sensitive functional groups in $\mathrm{CMCNa}$, which is the only smart derivative of cellulose with $\mathrm{pH}$-dependent behavior. Under acidic conditions ( $\mathrm{pH} \leq \mathrm{pKa}$ ), the carboxylic groups of $\mathrm{CMCNa}$ are protonated in form, causing a reduction in the concentration of the anionic groups and a decrease in swelling. As the $\mathrm{pH}$ of the medium exceeds the $\mathrm{pKa}$ of the acidic component of the polymer $(\mathrm{pH}>4)$, the carboxylic acid groups become deprotonated and repulsive electrostatic forces between the negatively charged sites $\left(\mathrm{COO}^{-}\right)$promote chain expansion, facilitating displacement of the molecules of media and enhancing swelling $[23,27]$. This research indicates that the optimum $\mathrm{pH}$ for the swelling of the polysaccharide/whey hydrogel is obtained when the $\mathrm{pH}$ of the solution exceeds the $\mathrm{pKa}$ of the given functional groups (herein, $\mathrm{COOH}$; $\mathrm{pKa} 4$ ). Similar results have been reported for $\mathrm{pH}$-sensitive cellulose-based hydrogel composites $[20,25,28]$. At $8<\mathrm{pH}<10$, swelling capacity reduces through the shielding effect of elevated $\mathrm{Na}+$ concentration in the media which causes inter-anionic repulsive imperfections leading to gradual instability and lacking of the dimensional integrity of the hydrogels in alkaline medium [29].

The hydrogel exhibits the potential for extreme sensitivity in relation to the concentration of ions in the water, as the presence of electrolytes in the solution decreases its capacity for absorption. As detailed in Figure 3, the swelling ratio for H5CA drops when the ionic strength of the solution is high. These findings are in agreement with those reported in the literature [30,31], wherein the swelling capacity of the tested hydrogels demonstrates the same trend through $\mathrm{OH}^{-}$being present in the basic media. In the saline solution, osmotic pressure increases due to the presence of ions, causing desorption of water from the hydrogel [31]; the lowest SR was observed in this medium as a consequence. At low ionic strength, the concentration of charges within the hydrogel network exceeds that of salt in the external solution, and this ion-swelling pressure causes the hydrogel films to expand [32]. The results show that the water absorbency of the polysaccharide/whey hydrogel strongly depends on the salt concentration present in the water. Therefore, it should be noted that the swelling behavior of the hydrogel could alter accordingly in an environment with high ionic strength.

3.1.2. Effect of Concentration of Citric Acid and Degree of Cross-Linking on the Swelling Properties of the Hydrogel

The amount of water that can be held by a sample directly relates to the concentration of the hydrophilic groups and cross-link density [31,33]. During the hydrogel synthesis, at higher temperatures, citric acid esterifies the high hydrophilic carboxylic groups of cellulose derivatives through the formation of a cyclic anhydride intermediate [34]. This reaction leads to new carboxylic acid units, which exhibited to property to forming new intramolecular anhydride groups with an adjacent carboxylic acid unit. The three-dimensional network of the prepared hydrogel is then formed and maintained by cross-linking points [12].

Figure 4 shows the influence of the CA on the water absorbed during the five swellingdrying-swelling cycles. At the highest concentration of CA (15\%), less uptake of water was observed, and the swelling capacity was reduced. However, the higher concentrations of CA promoted a rise in carboxyl content and hydrogels of greater structural stability were formed. In contrast, the hydrogel prepared with the lowest concentration of CA was weakly cross-linked, leading to the dissociation of the extremely hydrophilic carboxylic group of $\mathrm{CMCNa}$, thereby exerting an increase in equilibrium swelling and loss of the integrity of the hydrogel. These results clearly demonstrate an inverse correlation between cross-link density and swelling properties. In addition, the results of the gel fraction also confirm the effect of CA on the degree of crosslinking formed in the structure of the hydrogel polymer network and its swelling properties [35]. The more crosslinking that occurs in polymer network, the gel fraction value increases $(47.02 \% \pm 2.48 \%$ for $\mathrm{H} 5 \mathrm{CA}$, $58.45 \% \pm 1.42 \%$ for $\mathrm{H} 10 \mathrm{CA}$, and $67.65 \% \pm 1.52 \%$ for $\mathrm{H} 15 \mathrm{CA}$, respectively). The higher 
concentrations of crosslinking points resulted in lower swelling degree and the hydrogel polymer network became more rigid.

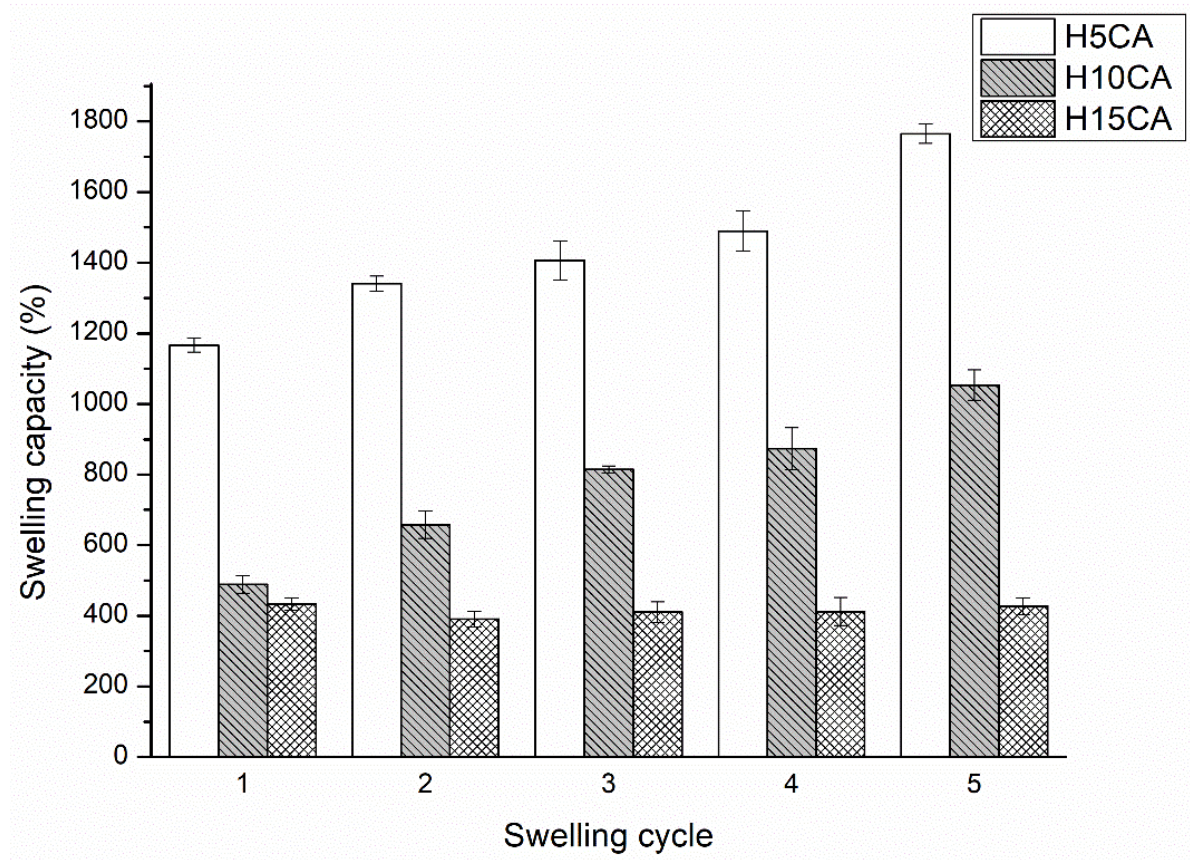

Figure 4. Swelling capacity (\%) of the hydrogels H5CA, H10CA and H15CA, following five consecutive re-swelling cycles. Data refer to mean values $\pm \mathrm{SD}(\mathrm{n}=3)$.

Another observation was that H5CA and H10CA exhibited reversible swelling behavior, with a rise in the swelling capacity during five swelling-drying cycles. This re-swelling ability significantly outperforms that of any cellulosic superabsorbent material reported in the literature [36-38], which has shown a rather declining trend with each cycle of swelling-deswelling.

\subsection{Hydrogel Morphology}

The effects of the concentration of the cross-linking agent on the surface morphology and internal structure of the hydrogel are detailed in Figures 5 and 6, respectively. The micrographs in Figure 5A-C illustrate the surfaces of the hydrogels supplemented with the various concentrations of the cross-linking agent, while Figure 6 shows their cross sections. Unlike surface morphology (Figure 5), which is largely unaffected by the increase in CA content, the inner structure becomes more compact in form. Figure $6 \mathrm{~A}$ reveals the hydrogel with the lowest concentration of CA (5\%) possesses a sponge-like structure, while the higher concentrations are denser in this respect. The inner structures observed correspond with the swelling data. Water uptake is greater and occurs faster in the sponge-like structure, due to the presence of cavities that facilitate the entry and flow of the media.
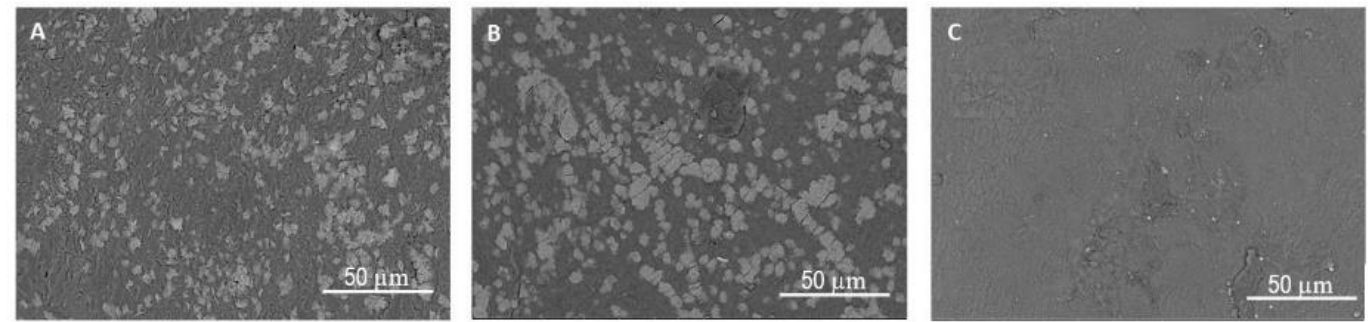

Figure 5. SEM micrographs of the surface of the dried hydrogels with the CA cross-linking agent at the concentrations of (A) $5 \% w / w$; (B) $10 \% w / w$ and (C) $15 \% w / w$. 

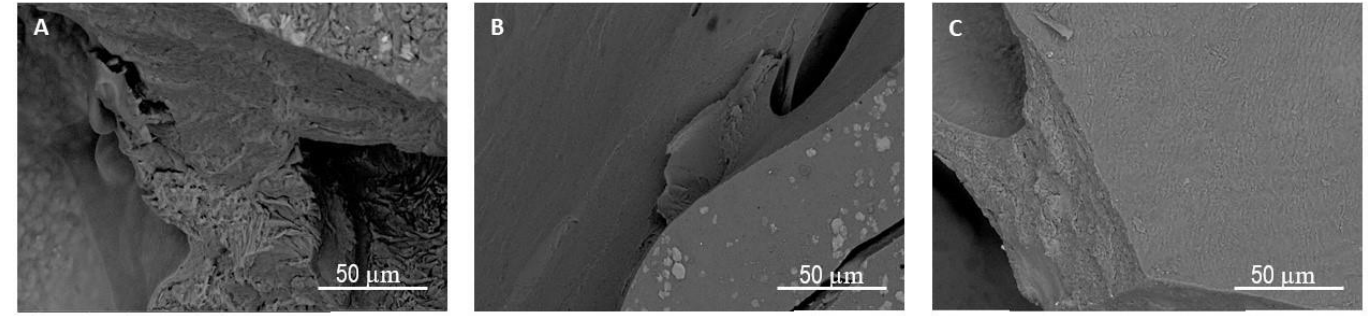

Figure 6. Cross sections of the dried hydrogels with the CA cross-linking agent at the concentrations of (A) $5 \% w / w$; (B) $10 \% w / w$ and (C) $15 \% w / w$.

\subsection{Water Retention in Soil}

Assessing the capacity for water retention in soil is important for understanding of the potential of the hydrogel as a soil conditioner. The graph in Figure 7 shows a continuous decrease in such capacity in soil and loss of water over the course of a month. Water content in the soil, monitored over several days following the first irrigation, was significantly affected by the presence of the hydrogel. The soil samples containing hydrogel possessed substantially more humidity, which confirms their capacity for water uptake. The soil with hydrogel H15CA demonstrated a higher level of water retention exceeding that of pure soil by almost 30\%. As the humidity in the soil decreased, the water absorbed by the hydrogel was slowly released, through a mechanism of diffusion [12]. Consequently, agricultural land with soil containing the hydrogel could possess more moisture during periods following irrigation or rain than otherwise, since water would be gradually released from the added material at any times of subsequent dryness [12,39].

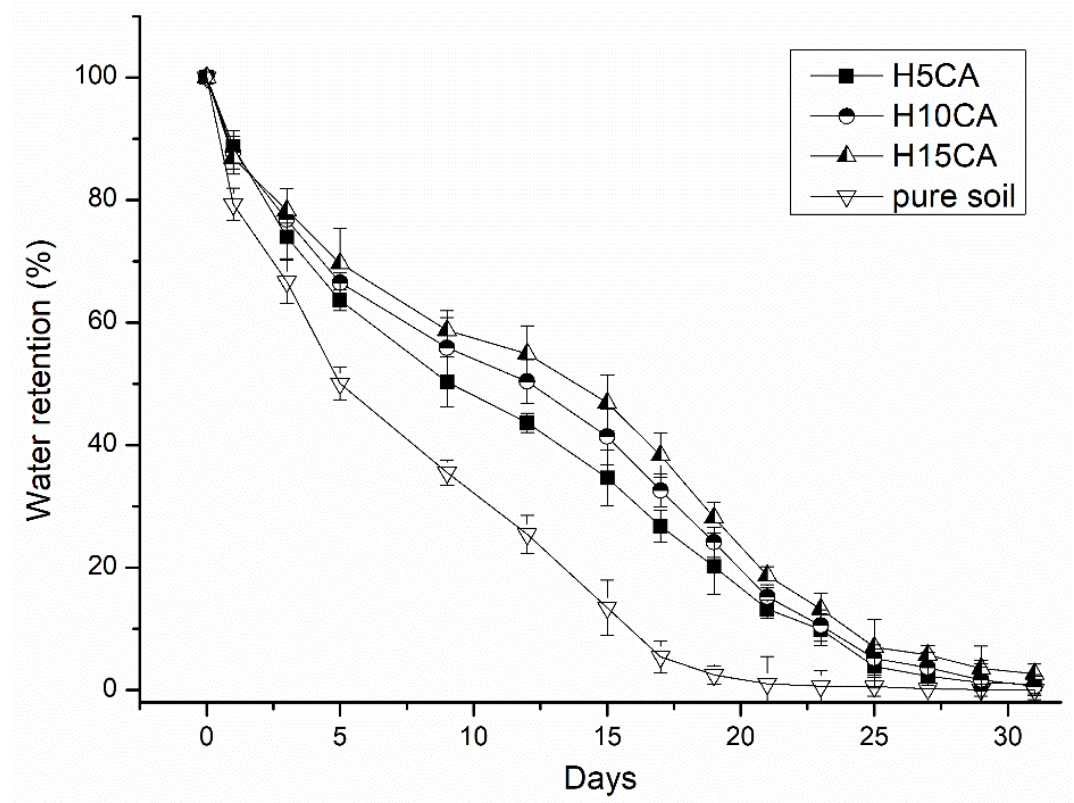

Figure 7. Water retention capacity (\%) of pure soil and soil containing the hydrogels H5CA, H10CA and H15CA; data refer to mean values \pm SD $(n=3)$.

\subsection{Water Re-Absorption in Soil}

The number of swelling-drying cycles carried out provided information on how reusable the hydrogel was in soil (Figure 8). The samples were gauged for swelling capacity in soil four times; this required that the moist soil was dried to constant weight after each swelling cycle. Each cycle was performed under identical conditions. The results show that the soil amended by the hydrogel was able to repeatedly absorb and retain water after each instance of drying. Adding hydrogel H15CA into the soil resulted in a rise in the absorption capacity compared to pure soil, although variations were observed 
in water retention values for each swelling-drying cycle. The greatest level of water retention occurred in the second cycle, followed by a gradual drop in the third and fourth. This decrease in the water absorption capacity might have been caused by the hydrogel experiencing degradation and/or variation in its inner structure, as well as change in particle size and ionic osmotic pressure [31]. It should be noted that the swelling degree of the hydrogel could be lower in soil than any values discerned for swelling in distilled water. Since each hydrogel particle in the soil was surrounded by particles of soil under limited pressure from the given environment, water uptake was somewhat diminished.

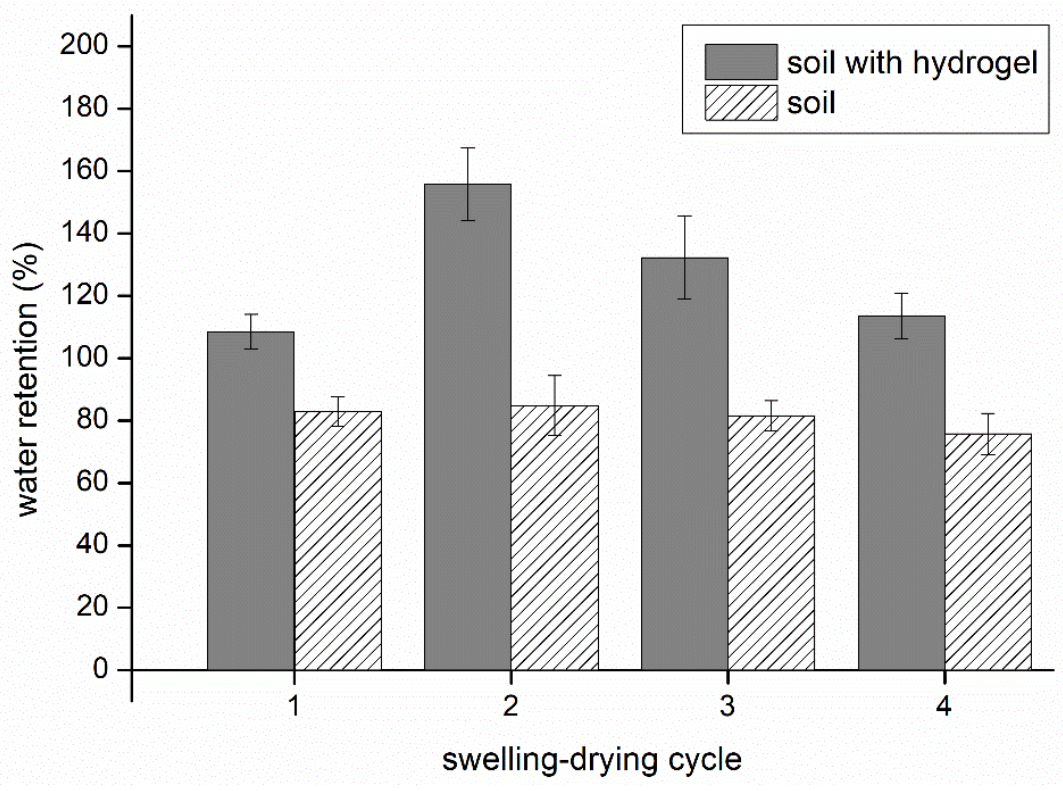

Figure 8. Water retention and re-absorption of hydrogel H5CA in soil during four swelling-drying cycles.

\subsection{Release Study}

The hydrogel samples were loaded with $\mathrm{KNO}_{3}$ and urea, either separately or in combination at the mass ratio of 1:1. The hydrogels soaked in the solutions with a single component reached saturation within different periods- $6 \mathrm{~h}$ for urea and $1 \mathrm{~h}$ for $\mathrm{KNO}_{3}$; once saturation had occurred, the given hydrogels were loaded with $72 \%(0.8 \mathrm{~g})$ of the initial amount of urea and $61 \%(0.6 \mathrm{~g})$ of $\mathrm{KNO}_{3}$. Variations in maximum load and the time in which such loading is achieved are influenced by the chemical structure and solubility of the compounds utilized. Molecular weight and molecular interaction between hydrogel and solute (fertilizer) plays a crucial role in this, since the fertilizers are loaded after preparation of the material, the mechanism for this being diffusion within the hydrogel from the surrounding solution [40]. The swelling of $\mathrm{KNO}_{3}$ is controlled by the osmotic pressure of the hydrogel which results from the difference between the mobile ion concentrations between the interior of the hydrogel and external swelling medium [41]. $\mathrm{KNO}_{3}$ reached saturation faster than urea, although the final content is affected by the mobility of the ions within the hydrogel structure and solvation. As for the process for the combined load, decrease and inversion in encapsulation efficiency were observed. At equilibrium, only $43 \%(0.5 \mathrm{~g})$ of urea and $52 \%(0.5 \mathrm{~g})$ of $\mathrm{KNO}_{3}$ were loaded into the hydrogels, potentially as a consequence of equilibrium being affected by the greater volume $(200 \mathrm{~mL}$ in the combined load vs. $100 \mathrm{~mL}$ separately). The differences in cross-link density between the three formulations affected the swelling of the hydrogels, in addition to their release mechanisms and kinetics.

The curves in Figure 9 show that release was rapid for both urea and $\mathrm{KNO}_{3}$ from the H5CA sample but slower for the H15CA one. All the release profiles demonstrate an intense initial burst that eases off, with over $80 \%$ of the loaded compound being released within 5 days. 

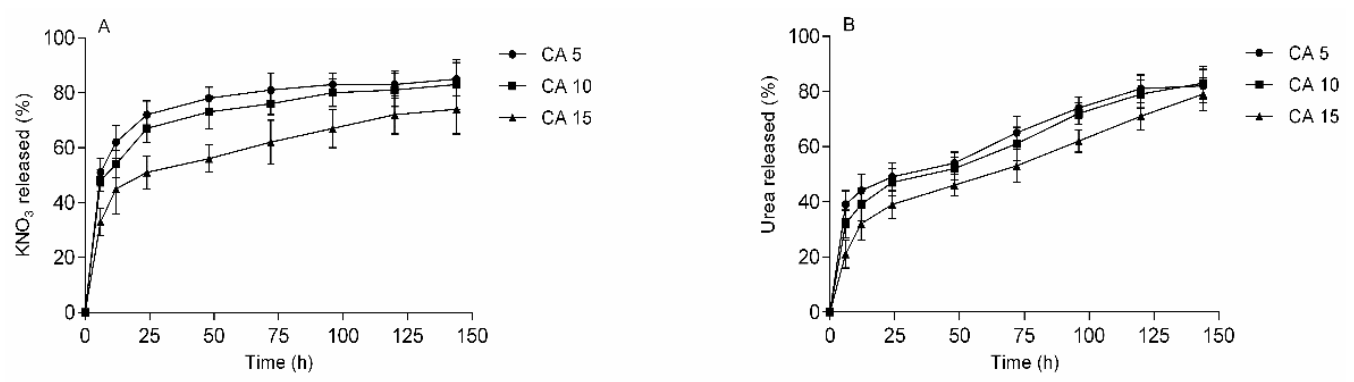

Figure 9. Release of (A) KNO3 and (B) urea from the hydrogel formulations; the experiments were performed in distilled water at room temperature; data refers to mean values $\pm S D(n=3)$.

The release profiles for the separate substances (Figure 9A,B) reveal an initial rapid burst took place (Figure 10). The burst peaked at the maximum value for swelling ratio (swelling at equilibrium). This burst release is a result of higher pore size of hydrogel matrix. The electrostatic repulsive effect between the carboxyl groups of hydrogel enhanced the porosity and thus molecules of fertilizer are easily released from the hydrogel matrix [29]. Sample H5CA achieved the highest such burst, while the lowest was seen for H15CA, indicating an inverse correlation with the cross-link density (increasing the concentration of CA resulted in a higher number of cross-linking points and the formation of a more compact microstructure). The samples with urea showed slower release profiles than $\mathrm{KNO}_{3}$ due to the occurrence of non-covalent interactions with macromolecular chains, in particular hydrogen bonds between the amino and hydroxyl groups.
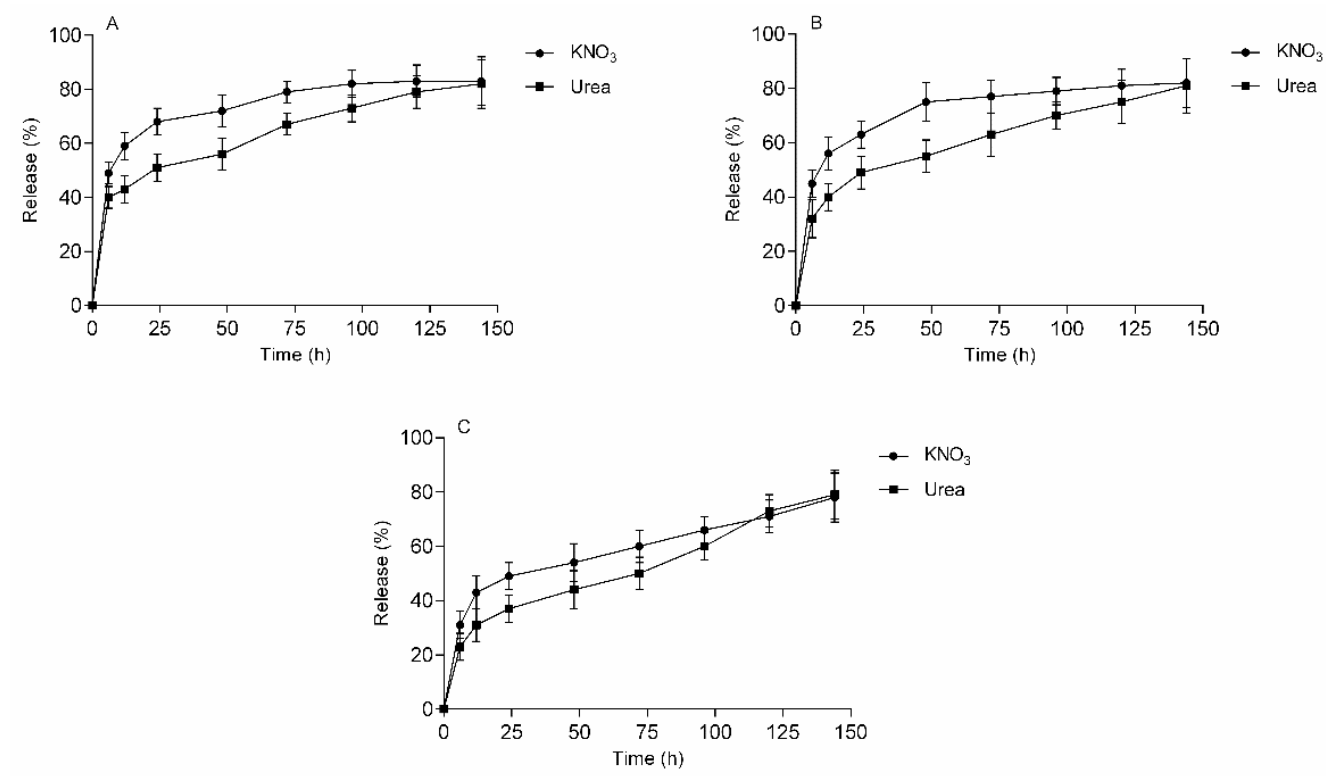

Figure 10. Simultaneous release of potassium nitrate and urea from (A) H5CA, (B) H10CA and (C) H15CA; as performed in distilled water at room temperature; data refer to mean values $\pm \mathrm{SD}(\mathrm{n}=3)$.

No statistical difference existed between the simultaneous release profiles detailed in Figure $10(p<0.05)$, suggesting the components neither interacted with each other, e.g., chemically, nor was there any effect on the release or the interaction with the hydrogel matrix. No alterations in the polysaccharide- $\mathrm{KNO}_{3}$ or polysaccharide-urea were observed either, due to the simultaneous presence of the fertilizers. 
In order to determine the nature of diffusion of fertilizer from hydrogel and relationship with the composition and structure of the hydrogel, the data were processed on the basis of the power of law Equation (8):

$$
\frac{\mathrm{M}_{\mathrm{t}}}{\mathrm{M}_{\mathrm{eq}}}=k \mathrm{t}^{\mathrm{n}}
$$

where $\mathrm{M}_{\mathrm{t}}$ and $\mathrm{M}_{\mathrm{eq}}$ denote the urea and potassium nitrate diffused from the hydrogel at time $t$ and the point of equilibrium, respectively [42]. The ratio of $M_{t}$ to $M_{e q}$ represents the fertilizer fractional release in time $(\mathrm{t})$, while $\mathrm{k}$ is a constant related to the polymer structure. Plotting $\ln \left(\mathrm{M}_{\mathrm{t}} / \mathrm{M}_{\mathrm{eq}}\right)$ vs. $\ln \mathrm{t}$ (time) gives coefficient $\mathrm{n}$ that describes the type of diffusion which depends upon the interaction in between fertilizer and the components of hydrogel matrix. The result of diffusion coefficient (n), correlation coefficient, $R^{2}$ and release mechanism is given in Table 2. The classification of diffusion mechanism of the fertilizer from the polymeric matrix is as follows: $n=0.5$ reveals the Case I or Fickian diffusion (rate of diffusion is much less than the polymer relaxation), $\mathrm{n}=1$ signifies the case II diffusion (diffusion is greater than time of polymer relaxation) and $\mathrm{n}$ between 0.5 and 1.0 signifies the non-Fickian or anomalous diffusion (diffusion and relaxation time is comparable) $[4,43]$. The $\mathrm{n}$ values were found to be $0.66-0.95$ indicating the release of fertilizer from the loaded hydrogel samples follows a non-Fickian diffusion and Case II diffusion in case of sample HCA5.

Table 2. Release exponent $(n)$, correlation coefficient $\left(\mathrm{R}^{2}\right)$ and diffusion mechanism at different hydrogel formulations.

\begin{tabular}{ccccc}
\hline Samples & Fertilizer & $\boldsymbol{n}$ & $\mathbf{R}^{\mathbf{2}}$ & Release Mechanism \\
\hline \multirow{2}{*}{ HCA5 } & urea & 0.92 & 0.98 & Non-Fickian \\
& $\mathrm{KNO}_{3}$ & 0.95 & 0.99 & Case II diffusion \\
\multirow{2}{*}{ HCA10 } & urea & 0.66 & 0.97 & Non-Fickian \\
& $\mathrm{KNO}_{3}$ & 0.81 & 0.99 & Non-Fickian \\
\multirow{2}{*}{ HCA15 } & urea & 0.69 & 0.99 & Non-Fickian \\
& $\mathrm{KNO}_{3}$ & 0.73 & 0.98 & Non-Fickian \\
\hline
\end{tabular}

The data also indicate a direct relationship between the citric acid content and the variation in the release mechanism. Increasing the concentration of CA increases the $n$ value, indicating a reduction of the chain mobility, due to the increase in the concentration of the crosslinking points. This means that a hydrogel with a higher crosslink density shows a more relaxation controlled swelling process [41].

\subsection{Biodegradation under Aerobic Conditions}

Biodegradation is a desirable property for a polymer intended for environmental and agricultural utilization. The course of biodegradation of the hydrogel in soil was quantified herein by detecting and measuring the production of carbon dioxide, through analysis of the gaseous phase using gas chromatography (GC). This provided a higher level of control and objectivity in assessing biodegradation than the usual process of measuring weight loss. The literature describes that the resultant $\mathrm{CO}_{2}$ directly relates to the mineralization of the supplied carbon source via bacterial respiration [44]. Aerobic microbes use oxygen as an electron acceptor, breaking down organic chemicals into smaller organic compounds with $\mathrm{CO}_{2}$ and by-products of water. Polymer biodegradation proceeds as follows: (i) attachment of the microorganism to the surface of the polymer, whereby extracellular enzymes secreted by the organism cause the primary chain to cleave, leading to the formation of lowmolecular-weight fragments, such as oligomers, dimers or monomers (depolymerization); (ii) growth pertaining to the microorganism, biomass uptake and metabolism, whereby low-molecular-weight compounds of the polymer are further utilized by the microbes as a 
carbon source; and (iii) ultimate degradation of the polymer (biomass $+\mathrm{O}_{2} \rightarrow \mathrm{CO}_{2}+\mathrm{H}_{2} \mathrm{O}$ ) (mineralization) [45,46].

Figure 11 plots the mineralization of carbon dioxide of the hydrogel samples during the biodegradation process. They all started to produce significant amounts of carbon dioxide immediately, potentially stemming from the mineralization of the biodegradable whey-polysaccharide material. Notably, the curves for them continued to rise gradually, reaching approximately $30 \%$ of mineralization for $\mathrm{H} 15 \mathrm{CA}$ and $35 \%$ for $\mathrm{H} 10 \mathrm{CA}$, respectively. The level recorded for sample H5CA surpassed this, though, extending to almost $50 \%$, with the curve still displaying a positive trend; this biodegraded more rapidly due to the low cross-linking of the hydrogel structure. Since the material contained whey and derivatives of cellulose, biodegradation of the low cross-linked hydrogel was probably caused by a major increase in the active surface area, resulting in more efficient action by the degrading microorganisms [15]. Another possible factor behind the extent of biodegradation is that the whey could have constituted an additional nutrient for the degrading microorganisms [9].

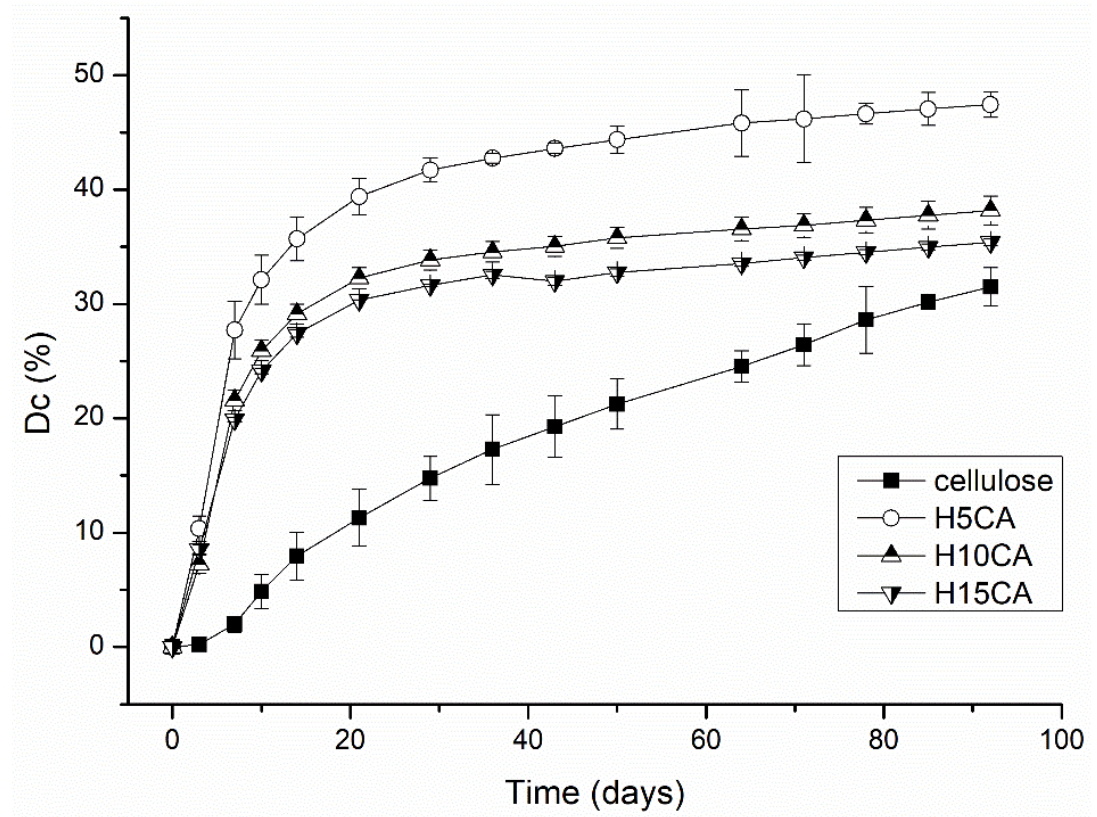

Figure 11. Mineralization curves for the various cross-linked samples, including reference material (cellulose).

Based on the results of the soil burial test, it was evident that the compounds forming the hydrogel—whey and cellulose derivatives, were degraded by microorganisms in the soil, despite its inherent cross-linked structure (Table 3).

Table 3. Percentage degradation of hydrogels using soil burial method.

\begin{tabular}{ccccc}
\hline \multirow{2}{*}{ Sample Designation } & \multicolumn{4}{c}{ Weight Loss (\%) at Different Time Intervals } \\
\cline { 2 - 5 } & 5 Days & 10 Days & 15 Days & 20 Days \\
\hline H10CA & 55.4 & 67.5 & 85.5 & 95.2 \\
H15CA & 54.6 & 62.8 & 80.8 & 87.4 \\
\hline
\end{tabular}

The visual changes the hydrogels underwent during the 20 days of degradation are presented in Figure 12 with H15CA as the example. As is plainly visible in the photographs, the size and shape of the hydrogel changed through exposure to the soil environment over time, undergoing visible reduction in the process. After this period, no further fragmentation was observed. The loss of physical integrity is likely due to the composition of the whey/polysaccharide-based hydrogel, which increases the surface availability for colonization by microorganisms, thereby hastening biodegradation. Therefore, it would 
be appropriate to enrich such a hydrogel with natural antimicrobial substances that will increase its sustainability in the soil environment.

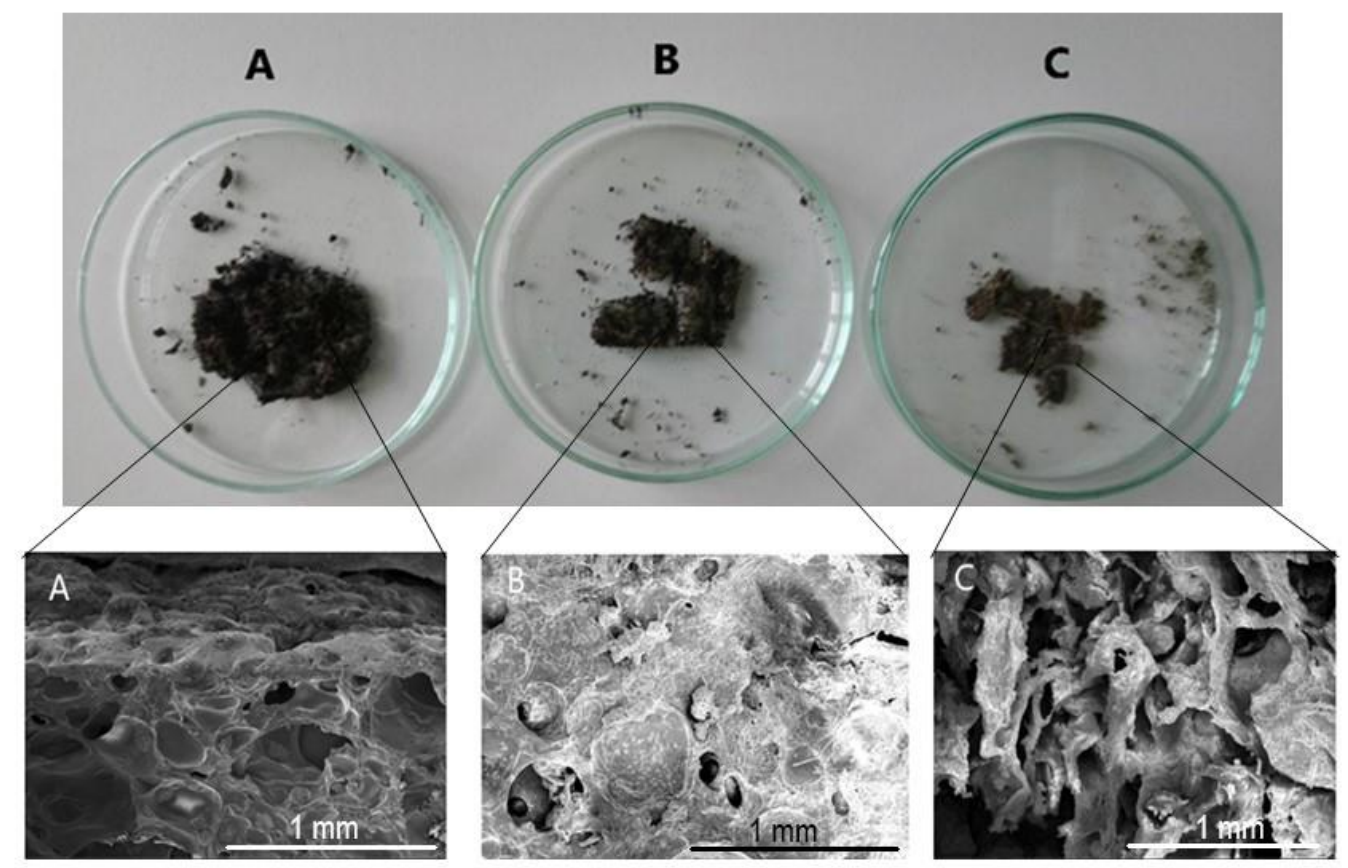

Figure 12. Visual degradation and SEM micrographs of hydrogel H15CA after (A) 5 days, (B) 10 days and (C) 20 days in soil, respectively.

The SEM micrographs depict the obvious formation of cavities in the inner structure. A stark comparison can be made with the micrograph in Figure 6C of the hydrogel prior to being buried in the soil, revealing that the number and dimensions of the cavities increased over time, causing the structure to collapse after 20 days.

\subsection{FTIR Evaluation of Structural Change in the Hydrogel during Biodegradation Process}

FTIR studies were conducted to determine how the hydrogels changed in the soil environment during the biodegradation test. Figure 13 depicts the FTIR spectra for the hydrogel removed from the soil at certain intervals during the burial experiment.

The reference material (the cross-linked hydrogel of cellulose derivatives and acid whey) shows a broad peak at $3000-3600 \mathrm{~cm}^{-1}$, attributed to the stretching vibration of the -OH ascribed to the hydroxyl groups of CA and cellulose derivatives CMC and HEC [10]. The two peaks at $2852 \mathrm{~cm}^{-1}$ and the band at $2926 \mathrm{~cm}^{-1}$ pertain to $\mathrm{C}-\mathrm{H}$ stretching of the $-\mathrm{CH}_{2}$ and $-\mathrm{CH}_{3}$ groups and is characteristic of a cross-linked hydrogel. The peak at $1327 \mathrm{~cm}^{-1}$ expresses the presence and bending vibrations of $-\mathrm{CH}_{2}-\mathrm{O}-\mathrm{CH}$ groups. Another at $1747 \mathrm{~cm}^{-1}$ is attributed to carbonyl $(-\mathrm{HC}=\mathrm{O})$ stretching [47]. That at $1632 \mathrm{~cm}^{-1}$ denotes the carbonyl band of esters formed during cross-linking and the carbonyl band of free carboxylic acid groups, whose presence is an indication of interaction between the CA and the polymer [48]. The characteristic peak at $1050-1100 \mathrm{~cm}^{-1}$ is typical for the absorption bands of $\mathrm{CMCNa}$, related to the $\mathrm{C}-\mathrm{O}$ stretching vibration of the alcoholic group [10].

The intensity of some peaks for the degraded hydrogel were seen to be lower than those described above, and some had shifted to a different region of the wave number during biodegradation. For example, such a decrease in intensity is evident in the region of $1747 \mathrm{~cm}^{-1}$, an expression of ester groups formed by the occurrence of cross-linking with the citric acid. As the samples degrade, the strength of their carboxyl bonds diminishes. The ATR-FTIR spectrum for the hydrogel residues show peaks at 2852, 2400, 2300, 1747 and $1327 \mathrm{~cm}^{-1}$, which are reduced in intensity and potentially indicate the loss of functional groups through the microbial breakdown of the samples. It is probable that during 
biodegradation these cross-linking bonds were the most easily accessible to the enzymes secreted by the microbes, hence they were broken at the beginning of the degradation process. The FTIR spectra also show peaks related to the degradation of cellulose. For example, a new sharp peak at $1547 \mathrm{~cm}^{-1}$ is attributed to the presence of free-COOH groups [17], while $1420 \mathrm{~cm}^{-1}$ pertains to the stretching vibration of $\mathrm{COO}$ and is an indication of the carboxyl groups of $\mathrm{CMCNa}$. The peak at $1262 \mathrm{~cm}^{-1}$ denotes the stretching vibration of a new $\mathrm{C}-\mathrm{C}$ bond from components of the reacted CA and cellulose derivatives. Lastly, a sharp peak appears at $1054 \mathrm{~cm}^{-1}$ that is characteristic of the bending vibration of the -OH group.

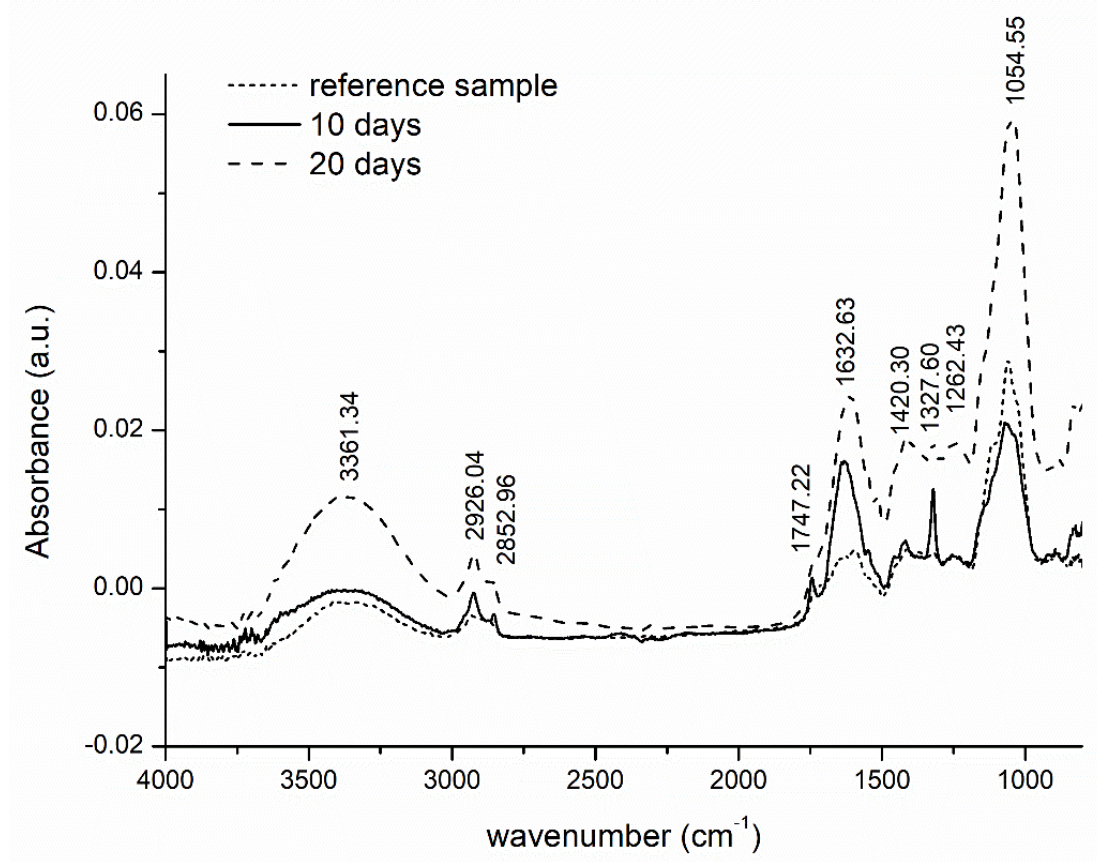

Figure 13. ATR-FTIR spectra for reference sample H15CA, and hydrogel sample after 10 days and 20 days in soil, respectively.

\section{Conclusions}

This paper describes a set of renewable and biodegradable hydrogels for agricultural use based on acid whey and derivatives of cellulose, prepared as a soil conditioner with the ability to release an added nutrient. The novel hydrogels demonstrate a high capacity for water absorption and properties that mark them out as applicable as carriers of a nutrient or fertilizer. They exhibit $\mathrm{pH}$-dependent, swelling behavior with a swelling ratio exceeding $1400 \%$ at the optimal $\mathrm{pH}$ and temperature, making them comparable with commercially available products. The novel hydrogels possess good swelling properties in soil and can be reused up to five times. The material is additionally capable of acting as a source of a nutritive whey agents for plants and a means of absorbing and releasing fertilizers in soil. It is also highly biodegradable in soil, since most of its compounds are mineralized when biodegradation commences, indicating its environmentally friendly composition. In summary, acid whey can be successfully used for the preparation of biopolymer biodegradable hydrogels and, thus, reduce the waste of the dairy industry. The novel polysaccharide/whey-based hydrogels are suitable for agricultural application, especially for water retention and nutrient release in soil, and may even have the potential to supersede synthetic, acrylic-based absorbents. 
Author Contributions: Conceptualization, S.D.; methodology, S.D. and A.D.M.; validation, S.D., M.D. and A.D.M.; formal analysis, S.D.; investigation, S.D. and A.D.M.; data curation, S.D., A.D.M., M.D. and P.D.; writing—original draft preparation, S.D.; writing-review and editing, A.D.M.; supervision, V.S.; project administration, V.S.; funding acquisition, V.S. All authors have read and agreed to the published version of the manuscript.

Funding: This research was funded by the Ministry of Agriculture of the Czech Republic (Project No. QK1910392), and the Ministry of Education, Youth and Sports of the Czech Republic (Grant No. RP/CPS/2020/002).

Data Availability Statement: The data presented in this study are available in article.

Conflicts of Interest: The authors declare no conflict of interest.

\section{References}

1. Calcagnile, P.; Sibillano, T.; Giannini, C.; Sannino, A.; Demitri, C. Biodegradable poly (lactic acid)/cellulose-based superabsorbent hydrogel composite material as water and fertilizer reservoir in agricultural applications. J. Appl. Polym. Sci. 2019, 136, 1-9. [CrossRef]

2. Mohamady Ghobashy, M. Chapter 12-The application of natural polymer-based hydrogels for agriculture. In Hydrogels Based on Natural Polymers; Chen, Y., Ed.; Elsevier: Amsterdam, The Netherland, 2020; pp. 329-356. ISBN 978-0-12-816421-1.

3. Saruchi; Kumar, V.; Mittal, H.; Alhassan, S.M. Biodegradable hydrogels of tragacanth gum polysaccharide to improve water retention capacity of soil and environment-friendly controlled release of agrochemicals. Int. J. Biol. Macromol. 2019, 132, 1252-1261. [CrossRef] [PubMed]

4. Saruchi; Kaith, B.S.; Jindal, R.; Kumar, V. Biodegradation of Gum tragacanth acrylic acid based hydrogel and its impact on soil fertility. Polym. Degrad. Stab. 2015, 115, 24-31. [CrossRef]

5. Isikci Koca, E.; Bozdag, G.; Cayli, G.; Kazan, D.; Cakir Hatir, P. Thermoresponsive hydrogels based on renewable resources. J. Appl. Polym. Sci. 2020, 137, 48861. [CrossRef]

6. Li, S.; Chen, G. Agricultural waste-derived superabsorbent hydrogels: Preparation, performance, and socioeconomic impacts. J. Clean. Prod. 2020, 251, 119669. [CrossRef]

7. Meng, Y.; Liu, X.; Li, C.; Liu, H.; Cheng, Y.; Lu, J.; Zhang, K.; Wang, H. Super-swelling lignin-based biopolymer hydrogels for soil water retention from paper industry waste. Int. J. Biol. Macromol. 2019, 135, 815-820. [CrossRef] [PubMed]

8. Song, B.; Liang, H.; Sun, R.; Peng, P.; Jiang, Y.; She, D. Hydrogel synthesis based on lignin/sodium alginate and application in agriculture. Int. J. Biol. Macromol. 2020, 144, 219-230. [CrossRef] [PubMed]

9. Akay, A.; Sert, D. The effects of whey application on the soil biological properties and plant growth. Eurasian J. Soil Sci. 2020, 9, 349-355. [CrossRef]

10. Gorgieva, S.; Kokol, V. Synthesis and application of new temperature-responsive hydrogels based on carboxymethyl and hydroxyethyl cellulose derivatives for the functional finishing of cotton knitwear. Carbohydr. Polym. 2011, 85, 664-673. [CrossRef]

11. Sannino, A.; Demitri, C.; Madaghiele, M. Biodegradable cellulose-based hydrogels: Design and applications. Materials 2009, 2, 353-373. [CrossRef]

12. Demitri, C.; Scalera, F.; Madaghiele, M.; Sannino, A.; Maffezzoli, A. Potential of cellulose-based superabsorbent hydrogels as water reservoir in agriculture. Int. J. Polym. Sci. 2013, 2013. [CrossRef]

13. Durpekova, S.; Filatova, K.; Cisar, J.; Ronzova, A.; Kutalkova, E.; Sedlarik, V. A Novel Hydrogel Based on Renewable Materials for Agricultural Application. Int. J. Polym. Sci. 2020, 2020, 8363418. [CrossRef]

14. Sarmah, D.; Karak, N. Biodegradable superabsorbent hydrogel for water holding in soil and controlled-release fertilizer. J. Appl. Polym. Sci. 2020, 137, 48495. [CrossRef]

15. Šerá, J.; Stloukal, P.; Jančová, P.; Verney, V.; Pekařová, S.; Koutný, M. Accelerated Biodegradation of Agriculture Film Based on Aromatic-Aliphatic Copolyester in Soil under Mesophilic Conditions. J. Agric. Food Chem. 2016, 64, 5653-5661. [CrossRef]

16. Seki, Y.; Altinisik, A.; Demircioğlu, B.; Tetik, C. Carboxymethylcellulose (CMC)-hydroxyethylcellulose (HEC) based hydrogels: Synthesis and characterization. Cellulose 2014, 21, 1689-1698. [CrossRef]

17. Maiti, M.; Kaith, B.S.; Jindal, R.; Jana, A.K. Synthesis and characterization of corn starch based green composites reinforced with Saccharum spontaneum L graft copolymers prepared under micro-wave and their effect on thermal, physio-chemical and mechanical properties. Polym. Degrad. Stab. 2010, 95, 1694-1703. [CrossRef]

18. Erizal, E. Synthesis of poly (acrylamide-co-acrylic acid)-starch based superabsorbent hydrogels by gamma radiation: Study its swelling behavior. Indones. J. Chem. 2012, 12, 113-118. [CrossRef]

19. de Stéfano, J.C.Q.; Abundis-Correa, V.; Herrera-Flores, S.D.; Alvarez, A.J. PH-sensitive starch-based hydrogels: Synthesis and effect of molecular components on drug release behavior. Polymers 2020, 12, 1974. [CrossRef]

20. Vaghani, S.S.; Patel, M.M.; Satish, C.S. Synthesis and characterization of pH-sensitive hydrogel composed of carboxymethyl chitosan for colon targeted delivery of ornidazole. Carbohydr. Res. 2012, 347, 76-82. [CrossRef]

21. Michalik, R.; Wandzik, I. A Mini-Review on Chitosan-Based Hydrogels with Potential for Sustainable Agricultural Applications. Polymers 2020, 12, 2425. [CrossRef] 
22. Demitri, C.; Madaghiele, M.; Grazia Raucci, M.; Sannino, A.; Ambrosio, L. Investigating the Structure-Related Properties of CelluloseBased Superabsorbent Hydrogels. In Hydrogels-Smart Materials for Biomedical Applications; IntechOpen: London, UK, 2019. [CrossRef]

23. Guilherme, M.R.; Aouada, F.A.; Fajardo, A.R.; Martins, A.F.; Paulino, A.T.; Davi, M.F.T.; Rubira, A.F.; Muniz, E.C. Superabsorbent hydrogels based on polysaccharides for application in agriculture as soil conditioner and nutrient carrier: A review. Eur. Polym. J. 2015, 72, 365-385. [CrossRef]

24. Saeed, A.M. Temperature effect on swelling properties of commercial polyacrylic acid hydrogel beads. Int. J. Adv. Biol. Biomed. Res. 2013, 1, 1614-1627.

25. Barbucci, R.; Magnani, A.; Consumi, M. Swelling Behavior of Carboxymethylcellulose Hydrogels in Relation to Cross-Linking, $\mathrm{pH}$, and Charge Density. Macromolecules 2000, 33, 7475-7480. [CrossRef]

26. Chang, C.; He, M.; Zhou, J.; Zhang, L. Swelling Behaviors of pH- and Salt-Responsive Cellulose-Based Hydrogels. Macromolecules 2011, 44, 1642-1648. [CrossRef]

27. Gupta, N.V.; Shivakumar, H.G. Investigation of Swelling Behavior and Mechanical Properties of a pH-Sensitive Superporous Hydrogel Composite. Iran. J. Pharm. Res. IJPR 2012, 11, 481-493.

28. Tulain, U.R.; Ahmad, M.; Rashid, A.; Malik, M.Z.; Iqbal, F.M. Fabrication of pH-Responsive Hydrogel and Its In Vitro and In Vivo Evaluation. Adv. Polym. Technol. 2018, 37, 290-304. [CrossRef]

29. Ganguly, S.; Das, N.C. Synthesis of Mussel Inspired Polydopamine Coated Halloysite Nanotubes Based Semi-IPN: An Approach to Fine Tuning in Drug Release and Mechanical Toughening. Macromol. Symp. 2018, 382, 1-8. [CrossRef]

30. Akhter, J.; Mahmood, K.; Malik, K.A.; Mardan, A.; Ahmad, M.; Iqbal, M.M. Effects of hydrogel amendment on water storage of sandy loam and loam soils and seedling growth of barley, wheat and chickpea. Plant Soil Environ. 2004, 50, 463-469. [CrossRef]

31. Abdallah, A.M. The effect of hydrogel particle size on water retention properties and availability under water stress. Int. Soil Water Conserv. Res. 2019, 7, 275-285. [CrossRef]

32. Sultana, S.; Rahaman, S.; Hasnine, S.M. Effect of Salinity on Swelling Behaviors of Superwater Absorbent Hydrogel Prepared from Carboxymethyl cellulose / Acrylamide Blends by Gamma Radiation. Am. J. Appl. Ind. Chem. 2018, 2, 20-26. [CrossRef]

33. Bukhari, S.M.H.; Khan, S.; Rehanullah, M.; Ranjha, N.M. Synthesis and Characterization of Chemically Cross-Linked Acrylic Acid/Gelatin Hydrogels: Effect of $\mathrm{pH}$ and Composition on Swelling and Drug Release. Int. J. Polym. Sci. 2015, 2015. [CrossRef]

34. Demitri, C.; Del Sole, R.; Scalera, F.; Sannino, A.; Vasapollo, G.; Maffezzoli, A.; Ambrosio, L.; Nicolais, L. Novel superabsorbent cellulose-based hydrogels crosslinked with citric acid. J. Appl. Polym. Sci. 2008, 110, 2453-2460. [CrossRef]

35. Wong, R.S.H.; Ashton, M.; Dodou, K. Effect of crosslinking agent concentration on the properties of unmedicated hydrogels. Pharmaceutics 2015, 7, 305-319. [CrossRef] [PubMed]

36. Alam, M.N.; Islam, M.S.; Christopher, L.P. Sustainable Production of Cellulose-Based Hydrogels with Superb Absorbing Potential in Physiological Saline. ACS Omega 2019, 4, 9419-9426. [CrossRef] [PubMed]

37. Wang, W.; Wang, J.; Kang, Y.; Wang, A. Synthesis, swelling and responsive properties of a new composite hydrogel based on hydroxyethyl cellulose and medicinal stone. Compos. Part. B Eng. 2011, 42, 809-818. [CrossRef]

38. Su, C.; Liu, J.; Yang, Z.; Jiang, L.; Liu, X.; Shao, W. UV-mediated synthesis of carboxymethyl cellulose/poly-N-isopropylacrylamide composite hydrogels with triple stimuli-responsive swelling performances. Int. J. Biol. Macromol. 2020, 161, 1140-1148. [CrossRef] [PubMed]

39. Rabat, N.E.; Hashim, S.; Majid, R.A. Effect of Different Monomers on Water Retention Properties of Slow Release Fertilizer Hydrogel. Procedia Eng. 2016, 148, 201-207. [CrossRef]

40. Li, J.; Mooney, D.J. Designing hydrogels for controlled drug delivery. Nat. Rev. Mater. 2016, 1, 16071. [CrossRef]

41. Siepmann, J.; Peppas, N.A. Modeling of drug release from delivery systems based on hydroxypropyl methylcellulose (HPMC). Adv. Drug Deliv. Rev. 2001, 48, 139-157. [CrossRef]

42. Chen, J.; Liu, M.; Liu, H.; Ma, L. Synthesis, swelling and drug release behavior of poly $(N, N-$ diethylacrylamide-co- $N$ hydroxymethyl acrylamide) hydrogel. Mater. Sci. Eng. C 2009, 29, 2116-2123. [CrossRef]

43. Bajpai, A.K.; Giri, A. Water sorption behaviour of highly swelling (carboxy methylcellulose-g-polyacrylamide) hydrogels and release of potassium nitrate as agrochemical. Carbohydr. Polym. 2003, 53, 271-279. [CrossRef]

44. Rose, R.S.; Richardson, K.H.; Latvanen, E.J.; Hanson, C.A.; Resmini, M.; Sanders, I.A. Microbial degradation of plastic in aqueous solutions demonstrated by $\mathrm{CO}_{2}$ evolution and quantification. Int. J. Mol. Sci. 2019, 21, 1176. [CrossRef]

45. Fesseha, H.; Abebe, F. Degradation of plastic materials using microorganisms: A review. Public Health Open J. 2019, 4, 57-63. [CrossRef]

46. Tosin, M.; Pischedda, A.; Degli-Innocenti, F. Biodegradation kinetics in soil of a multi-constituent biodegradable plastic. Polym. Degrad. Stab. 2019, 166, 213-218. [CrossRef]

47. Mali, K.K.; Dhawale, S.C.; Dias, R.J.; Dhane, N.S.; Ghorpade, V.S. Citric acid crosslinked carboxymethyl cellulose-based composite hydrogel films for drug delivery. Indian J. Pharm. Sci. 2018, 80, 657-667. [CrossRef]

48. Tavera-Quiroz, M.J.; Feria Díaz, J.; Pinotti, A. Characterization of Methylcellulose Based Hydrogels by Using Citric Acid as a Crosslinking Agent. Int. J. Appl. Eng. Res. 2018, 13, 13302-13307. 